\title{
Evaluation of empirical methods for estimating potential evaporation values in northeast France
}

\author{
Kátia Vanessa Bicalho ${ }^{1, a}$, Larissa Camporez Araujo ${ }^{1}$, Yu-Jun Cui ${ }^{2}$ and Bruno Teixeira Dantas ${ }^{1}$ \\ ${ }^{1}$ Federal University of Espirito Santo, Civil Engineering Department, Vitória, ES, Brazil \\ ${ }^{2}$ ENPC, Cermes, France
}

\begin{abstract}
This study presents and discusses the field monitoring of an experimental embankment divided into two symmetrical sections constructed with two different fine-grained soils in the northeast of France. The field instrumentation included detailed monitoring of volumetric water content, matric suction and temperature within the embankment as well as measurements of meteorological data. The field measurements show that the used instrumentation worked well on monitoring the soil responses to the meteorological changes in the two soils. The study also evaluates different empirical methods for estimating potential evaporation (ET) values based on regional meteorological data. The results show a large variability observed on the ET values for the investigated site calculated by empirical methods or equations based on meteorological local date.
\end{abstract}

\section{Introduction}

It is accepted the importance of determining the changes in the soil properties, especially the changes in the soil water content and corresponding pore-water pressure, in the unsaturated region. The changes of soil water content in a drying soil sample are mainly dependent on the local environmental conditions, the initial water content and temperature values, the hydromechanical properties of the soil, and the boundary conditions at the soilatmosphere interface.

Severe changes in weather conditions will lead to significant changes in pore-water pressure of the soil resulting in heave or shrinkage and causing damage to the structures. Soil pore-water pressures can be changed under two principal mechanisms: infiltration or evapotranspiration. The water balance calculation enables the geotechnical designer to estimate the amount of water entering, retained within and exiting the earth embankments or fills. Evaporation from soil, which represents an important term in the water balance equation, is a significantly complex mechanism and difficult to quantify ([1]), occurring in the form of combined liquid and vapor transport both at the depth and ground surface.

Under field conditions it is not possible to separate completely the evaporation from transpiration, so the actual evapotranspiration, or the total water loss, is used to describe the amount of evapotranspiration. When soil moisture is depleted, the actual evapotranspiration will be limited by monthly precipitation (lower limit) and potential evapotranspiration (upper limit). The potential evapotranspiration, $E T$, can be defined as the maximum evaporation rate in the case of water availability. In the months when the potential evapotranspiration is less than the rainfall, actual evapotranspiration is closer to the potential value ([2]).

This study presents some results of the field monitoring of an experimental embankment divided into two symmetrical sections constructed with two different fine-grained soils in the northeast of France. This paper focus on understanding of soil-atmosphere fluxes in the embankment system over time, therefore, it places emphasis on the soil suction, volumetric water content, temperature and site-specific meteorological measurements.

The paper evaluates five different empirical methods or equations for estimating $E T$ values based on regional meteorological data: ([3]); ([4]); ([5]); ([6]); ([7]). Also, the study examines the use of simple water balance models based on precipitation and potential evaporation to assess soil suction and moisture conditions. It is assumed that the rainfall does not lead to ponding water on soil surface, i.e., the precipitation rate does not exceed the infiltration rate.

\section{Materials and methods}

\subsection{Description of the site and soils}

The embankment was constructed at Hericourt, in the Haute-Saone department (Franche-Comte region) in the northeast of France. It is exposed to a continental climate, with oceanic influences. The details of the embankment

\footnotetext{
a Corresponding author: kvbicalho@gmail.com
} 
construction and the experimental program are presented in $([8])$.

According to the unified soil classification system, the used two natural soils were classified as: $\mathrm{CL}$, an inorganic clay with low plasticity, and $\mathrm{CH}$, an inorganic clay with high plasticity. The French Soil Classification System classifies these soils into A2 and A4 groups, respectively. The clay-sized particles $(\leq 0.002 \mathrm{~mm})$ for the $\mathrm{CL}$ and $\mathrm{CH}$ soils are about $25-30 \%$ and $80-85 \%$ respectively. The used soils are quite common in occurrence in the region. Laboratory tests of the natural and treated soils were conducted to evaluate the appropriateness of the chosen treatment formulation and the batching.

The field instrumentation layout was symmetrical for the two sections of the embankment. The embankment consists of 17 layers made of the fill materials compacted to optimum water contents (Standard Proctor tests). The optimum water contents were determined by the intercept of the compaction curve with the degree of saturation line corresponding to $85 \%$.

A layer of the slope, approximately at mid-slope, was selected for the investigations and analyses. The selected layer, located at about $1,8 \mathrm{~m}$ from the embankment base, is instrumented with sensors, for measuring suction and water content, located close to allow estimation of the in situ soil water retention curves. The field instrumentation program generated a large amount of data; therefore, this paper summarizes some of this data in graphical form from April 2011 to November 2011.

The embankment was also equipped with a sitespecific meteorology station on the top surface to record the data every 30 minutes. The year of 2011 had a cumulative precipitation (rainfall) of $773 \mathrm{~mm}$ recorded by a French weather station at Luxeuil-les-Bains (located about $50 \mathrm{~km}$ from the site-specific meteorological station) compared with the average annual precipitation of $619 \mathrm{~mm}$ in France. It is possible to observe the different daily measurements between these two places due to the great distance between them.

In this paper, the meteorological data measured by the site-specific meteorological station is used in the investigations and analysis. The data used in this paper are: average monthly air temperature, $T$, relative humidity, $R h$, solar radiation, $R s$, and monthly per cent of daytime hours of the year $p$ (see Table 1).

\subsection{Description of the ET equations}

Several methods or equations can be used to estimate ET from standard meteorological observations. The following five empirical equations were selected to estimate ET in this study: ([3]); ([4]); ([5]); ([6]); and ([7]). The equations are evaluated in this paper due to the advantage that the methods offer in calculating ET by using only standard meteorological. Often one chooses a model to estimate ET based on the available data to calculate the model. Moreover they are widely accepted methods under a variety of climatic regimes and conditions.
The ET equations are briefly summarized here and the cited references are suggested for a more detailed discussion. The ET was calculated for the investigated region in 2011 when the weather data were directly measured in the investigated slope.

The empirical ([3]) method is widely used, even though the method is not recommended for use in areas that are not climatically similar to the developed area, in the eastern region of USA, where sufficient moisture water was available to maintain active transpiration. Moreover one should be aware that the soil temperature fluctuates daily and yearly affected mainly by changes in air temperature and solar radiation ([8]). The method for monthly ET (mm/month) is:

$$
E T_{p}^{\prime}=16\left(\frac{10 T}{I}\right)^{a}
$$

where $T$ is the mean temperature for the month (in ${ }^{\circ} \mathrm{C}$ ) for $0 T 26^{\circ} \mathrm{C}, I$ is the annual thermal index, i.e. the sum of monthly indices $I[i=(T / 5) 1.514], d$ is a correction factor which depends on latitude and month. In this paper, $d$ is defined equal to 1 ([9]), and,

$a=0.000000675 I 3-0.0000771 I 2+0.0179 I+0.492$

The equation developed by ([4]) defines the daily ET as a function of the air temperature, $T\left({ }^{\circ} \mathrm{C}\right)$, relative humidity, $R h$, and solar radiation, $R s\left(\mathrm{cal}^{\mathrm{cm}} \mathrm{cm}^{-2} \cdot \mathrm{d}^{-1}\right)$ :

$E_{T u r}=0.013 \cdot\left(\frac{T}{T+15}\right) \cdot\left(R_{s}+50\right) \cdot a_{t}$

where $a_{t}=1$ if the average daily relative humidity for equal or higher than $50 \%$, otherwise:

$a_{k}=\left(1+\frac{50-8 h}{70}\right)$

A combination of temperature and air relative humidity based equation (([5]) was used to estimate $E T$. The equation derived by ([5]) calculates the ET (mm/month) based on the mean monthly temperature, $T$ (in ${ }^{\circ} \mathrm{C}$ ), and air relative humidity, $R_{h}$ (in \%):

$$
E T_{\text {Rom }}=0.0018 \cdot(25+T)^{2} \cdot(100-R h)
$$

The air relative humidity is the ratio of the absolute humidity to the saturation humidity for the air temperature. The saturation humidity is directly proportional to the air temperature and, the evaporation ceases when the air relative humidity approaches to $100 \%$. Although ([9]) proposed an equation to calculated $\mathrm{R}_{\mathrm{h}}$, in this study the mean monthly relative humidity values measured at the instrumented area are adopted.

The equation proposed by ([6]) is well known in the western USA and has been used extensively elsewhere also ([6]):

$$
E T_{B C 1}=k p(0.46 T+0.83)
$$


where $T$ is mean temperature in ${ }^{\circ} \mathrm{C}, \mathrm{p}$ is percentage of total daytime hours for the period used out of total daytime hours of the year ( $365 \times 12)$, and $\mathrm{k}$ is a monthly consumptive use coefficient, depending on vegetation type, location and season. According to ([6]) for the growing season (May to October) $\mathrm{k}$ varies from 0.5 for orange tree to 1.2 for dense natural vegetation.

The equation suggested by ([7]) for estimating ET ( $\mathrm{mm} /$ day) is:

$E T_{x h=}=0,34, p \cdot T^{2 x}$

Soil moisture at a location varies depending on the amount of precipitation (rain or snow) and evaporation. The atmospheric water balance $(B)$, at a particular locality, can be written as:

$$
B=P-E T
$$

where $P$ is the precipitation and ET is the potential evaporation. During the period of excess water $(B$ positive), there is moisture available for ground-water recharge and runoff.

Table 1. The meteorological data at region from May to October in 2011.

\begin{tabular}{|c|c|c|c|c|}
\hline $\begin{array}{c}\text { Month } \\
(2011)\end{array}$ & $T\left({ }^{\circ} \mathrm{C}\right)$ & $R h(\%)$ & $P$ & $R s\left(\mathrm{MJ}_{\mathrm{m}}{ }^{-2} \cdot \mathrm{dia}^{-1}\right)$ \\
\hline May & 13.17 & 75.1 & 0.27 & 3.48 \\
\hline June & 17.18 & 77.9 & 0.32 & 3.46 \\
\hline July & 16.56 & 82.8 & 0.32 & 3.29 \\
\hline August & 18.30 & 85.8 & 0.31 & 3.16 \\
\hline September & 15.22 & 89.3 & 0.24 & 2.44 \\
\hline October & 9.01 & 93.0 & 0.16 & 1.47 \\
\hline
\end{tabular}

\section{Results and discussion}

Storms with heavy rainfall exceeding $50 \mathrm{~mm} /$ hour were not recorded in 2011 in the investigated site. Some rainy periods of heavy rain $(10-50 \mathrm{~mm} /$ hour $)$ were observed from May to July in 2011. A total of 34 rainfall events of moderate rain $(2.5-10 \mathrm{~mm} /$ hour $)$ was recorded in July 2011, the month with the highest precipitation in 2011. A total of 13 rainfall events of moderate rain (2.5 -10 $\mathrm{mm}$ /hour) was recorded in June 2011, and only one moderate rainfall event was recorded in May 2011. Cumulative total rainfall in May, June and July were 37.2 $\mathrm{mm} / \mathrm{month}, 85.8 \mathrm{~mm} / \mathrm{month}$, and $120.4 \mathrm{~mm} / \mathrm{month}$ respectively.

([1]) stated that air temperature and relative humidity gradients are generally not constant with the height above the soil surface, but they are approximately constant at heights of $0.5-2 \mathrm{~m}$ above the surface. The measurements show that the air temperatures are approximately constant at heights of $0.5 \mathrm{~m}$ and $1.5 \mathrm{~m}$ above the surface. A small difference of about $5-10 \%$ was observed in the air relative humidity recorded at $0.5 \mathrm{~m}$ and $1.5 \mathrm{~m}$ above the surface. The air close to the soil surface is warmer than it is higher up (at $0.5 \mathrm{~m}$ and $1.5 \mathrm{~m}$ above the soil surface) from April to August in 2011. The same trend is not observed in the months with lower temperatures (October and November 2011). Wind speeds between 0 and 5.5 $\mathrm{m} / \mathrm{s}$ were recorded in 2011 . The mean monthly wind speed was about $1.0 \mathrm{~m} / \mathrm{s}$ for the entire monitoring period. Wind speed is important because stronger winds cause more evapotranspiration ([8]).

Figure 1 presents the computed ET values and the measured precipitation (rainfall) for the investigated site in 2011. It is a means of characterizing the local climate. Figure 1 also shows a comparison between the mean monthly potential evaporation values calculated by the selected ET equations. According to the ET methods, ([3]) and ([4]), a water deficit ( $B$ negative) was observed from May to October 2011. The ET methods ([6]) and ([7]) indicate a period of water surplus ( $B$ positive) from May to September 2011, Hericourt, France. In October 2011 , B is negative (water deficit) according to the five adopted ET methods.

The results show a large variability observed on the $E T$ values for the investigated site calculated by empirical methods or equations based on meteorological local date. The difference observed in the five methods can be attributed to variations of measured input data (i.e., air relative humidity) during 2011. The equations of ([3]) and ([6]) considers only temperature as input data while, depending on the season and region, other variables like wind speed, humidity and solar radiation can determine the magnitude of ET. ([5]) considered temperature and air relative humidity as input data. The mean monthly solar radiation and wind speed measured values in the region remained essentially unchanged during the evaluation period; therefore, it may be reasonable the assumption of no influence of the solar radiation and wind speed on the evaporation considered by the used methods for the site in 2011 .

Even though, ([1]) showed that the ([3]) equation consistently underestimates the measured ET; ([10]) suggested that the ([3]) method overestimates ET where climate is relatively humid, while for arid and semiarid parts of China it produces an underestimation. ([9]) verified that for the region of their study, the constant 16 of the ([3]) method should be changed to 20. ([6]) suggest the values of $\mathrm{k}$ ranging from approximately 0.7 to 0.95 . Therefore some calibrations or changes in the models parameters may be required to improve the accuracy of the proposed equations. 


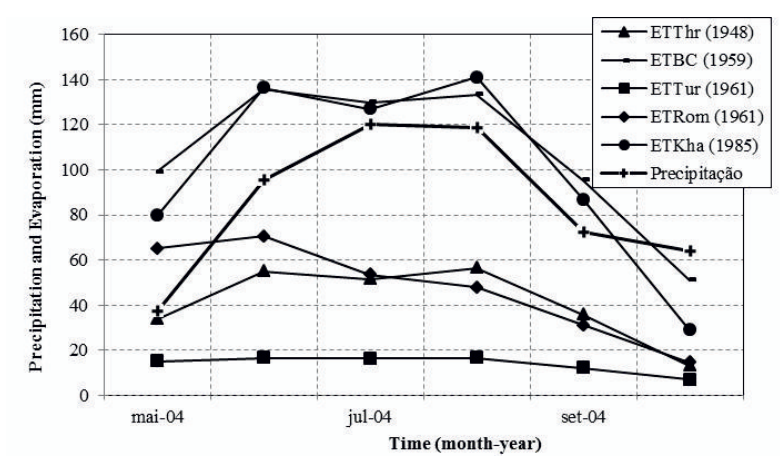

Figure 1. Precipitation ( $\mathrm{mm} / \mathrm{month})$ and the ET $(\mathrm{mm} / \mathrm{month})$ values by the empirical equations from $\mathrm{Thr}=([3])$; Tur $=$ $([4]) ;$ Rom $=([5]) ; \mathrm{BC}=([6]) ; \mathrm{Kha}=([7])$ from May to October 2011, Hericourt, France.

Figure 2 shows the in situ soil suction, volumetric water content and rainfall measurements collected daily from April to November in 2011. Figure 2a shows the in situ soil suction measurements for the three sensors installed at the same layer along the face of the embankment constructed with the lime treated clay: CL $+2 \% \mathrm{CaO}$. Suction is usually less than $200 \mathrm{kPa}$, and the pressure limit can be determined by the soil suction sensor. At each section of the slope the three Watermark soil suction sensors were placed at $0.25 \mathrm{~m}, 0.5 \mathrm{~m}$, and $0.75 \mathrm{~m}$ from the ground surface (mid-slope face). The measurements show similarities in the daily variations trend of suctions in the two treated fine-grained soils ([8]). The suction values are high near the ground surface, sensors placed at $-0.25 \mathrm{~m}$ of the slope face, during the period of water deficit (i.e., from April to June 2011) in the two investigated soils, and the fluctuation of the suction measurements generally decrease with depth.

The suction values observed in the high plasticity treated soil are generally lower than those at the correponding points in the lower plasticity treated soil, mainly due to the difference in the magnitude of the corresponding measured volumetric water content values: $39 \%-43 \%$ (lime treated $\mathrm{CH}$ ) and 29-35\% (lime treated CL). The maximum volumetric water content of a given soil volum is the saturated volumetric water content or the soil porosity. Considering the soil porosity value of about $53 \%$ for the lime treated $\mathrm{CH}$ and $43 \%$ for the lime treated CL, the degrees of saturation change from 74 to $81 \%$ in the investigated layer in the $\mathrm{CH}+4 \% \mathrm{CaO}$ section and from 68 to $81 \%$ in the investigated layer in the CL $+2 \% \mathrm{CaO}$ section.

The water content of the soil surface (TDR 39, located between SUC08 and SUC11) gradually decreased as the water moved down into the soil or evaporated, and the water content of the deep soil (TDR 38, located at $0.875 \mathrm{~m}$ from TDR39) remained almost constant in the lime treated CL soil. The same soil moisture response was not observed in the lime treated $\mathrm{CH}$ soil, in general, very small changes in the soil moisture were observed, even though the soil temperature values were different in the two slope locations. This can be explained by the differences in the permeability and water retention curves of the two soils ([11]). ([1]) reported that the rate of infiltration is affected by the permeability of the soil, its surface gradient and its water content or suction.
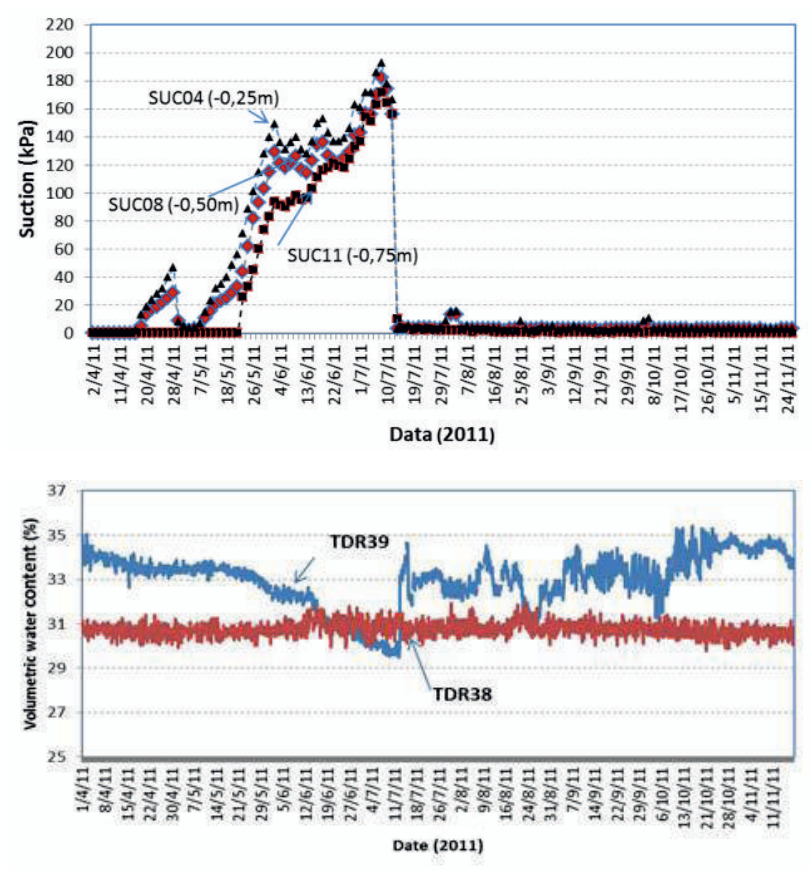

(b)

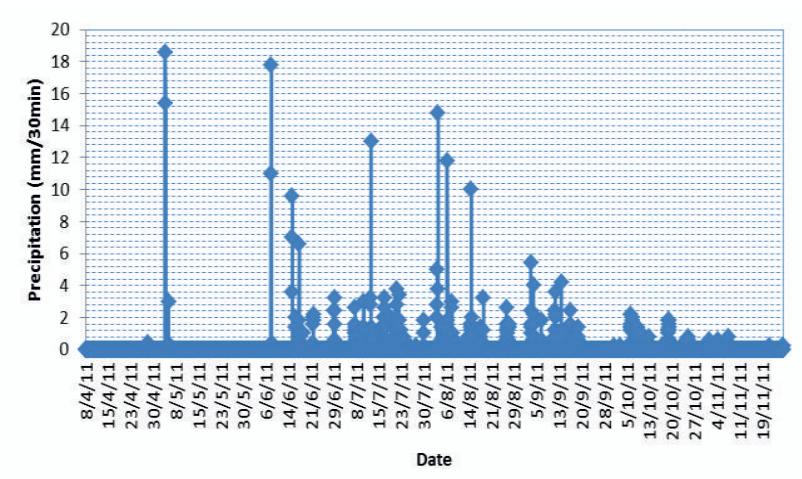

(c)

Figure 2. The daily measured (a) soil suctions, (b) volumetric water contents in different locations from slope face (midslope, $\mathrm{CL}+2 \% \mathrm{CaO}$ section), and (c) rainfall, from April to November, 2011.

\section{Conclusions}

In general, no significant response to the rainfall events was observed during the dry period in the treated soils. The rainfall events were recorded in 30 minutes period, and the results show that they have a significant effect on the suction changes at the start of the wet period (i.e., after long dry period) in the two soils.

The atmospheric water balance derived from monthly estimated potential evaporation based on standard meteorological observations may be used to estimate the period of water deficit observed in the daily suction and moisture measurements. However the ET obtained by the used methods involves some level of empiricism, and therefore some calibrations or changes in the models 
parameters may be required to improve the accuracy of the proposed equations.

\section{References}

1. E. Blight, Interactions between the atmosphere e the earth. Geotech., 47, 4, 715-767 (1997).

2. C. W. Fetter, Applied Hydrogeology, 3rd ed. Macmillan College Publishing, Inc., New York, 616 p. (1994).

3. C. W. Thornthwaite, An approach toward a rational classification of climate. Geogr. Rev., 38: 55-94 (1948).

4. L. Turc, Estimation of irrigation water requirements, potential evapotranspiration: a simple climatic formula evolved up to date, Ann. Agron., 12, 13-49. (1961).

5. V. A. Romanenko, Computation of the autumn soil moisture using a universal relationship for a large area. Kiev: Ukrainian Hydro meteorological Research Institute, 3 p. (1961).

6. H. F. Blaney, W. D. Criddle, Determining consumptive use e irrigation water requirements. Tech. Bull., U. S. Dep. of Agric. 1275 (1962), 59 p.

7. N. S. Kharrufa (1985), Simplified equation for evapotranspiration in arid regions". Beiträge zur Hydrologie, Kirchzarten, Sonderheft 5.1, 39-47, (1985).

8. K. V. Bicalho, G. P. D. Vivacqua, Y-J Cui, M. Froumentin, D. Mercadier, A.M. Tang, Experimental Investigation of Soil-Atmosphere Interaction in an Instrumented Embankment constructed with two treted clays. Soils \& Rocks, 38, 149 - 162 (2015).

9. C. - Y. Xu, V. P. Singh, A review on monthly water balance models for water resources investigations. Water Resour. Manag 12 (1998), 31-50.

10. D. Chen; G. Gao; C-Y Xu; J. Guo; G. Ren. Comparison of the Thornthwaite method and pan data with the standard Penman-Monteith estimates of reference evapotranspiration in China. Climate Research, 28:1, p. 123-132. (2005).

11. K. V. Bicalho, Modeling Water Flow in an Unsaturate Compacted Soil. PhD. Thesis, Department of Civil Engineering, University of Colorado, Boulder, 235 p. (1999). 